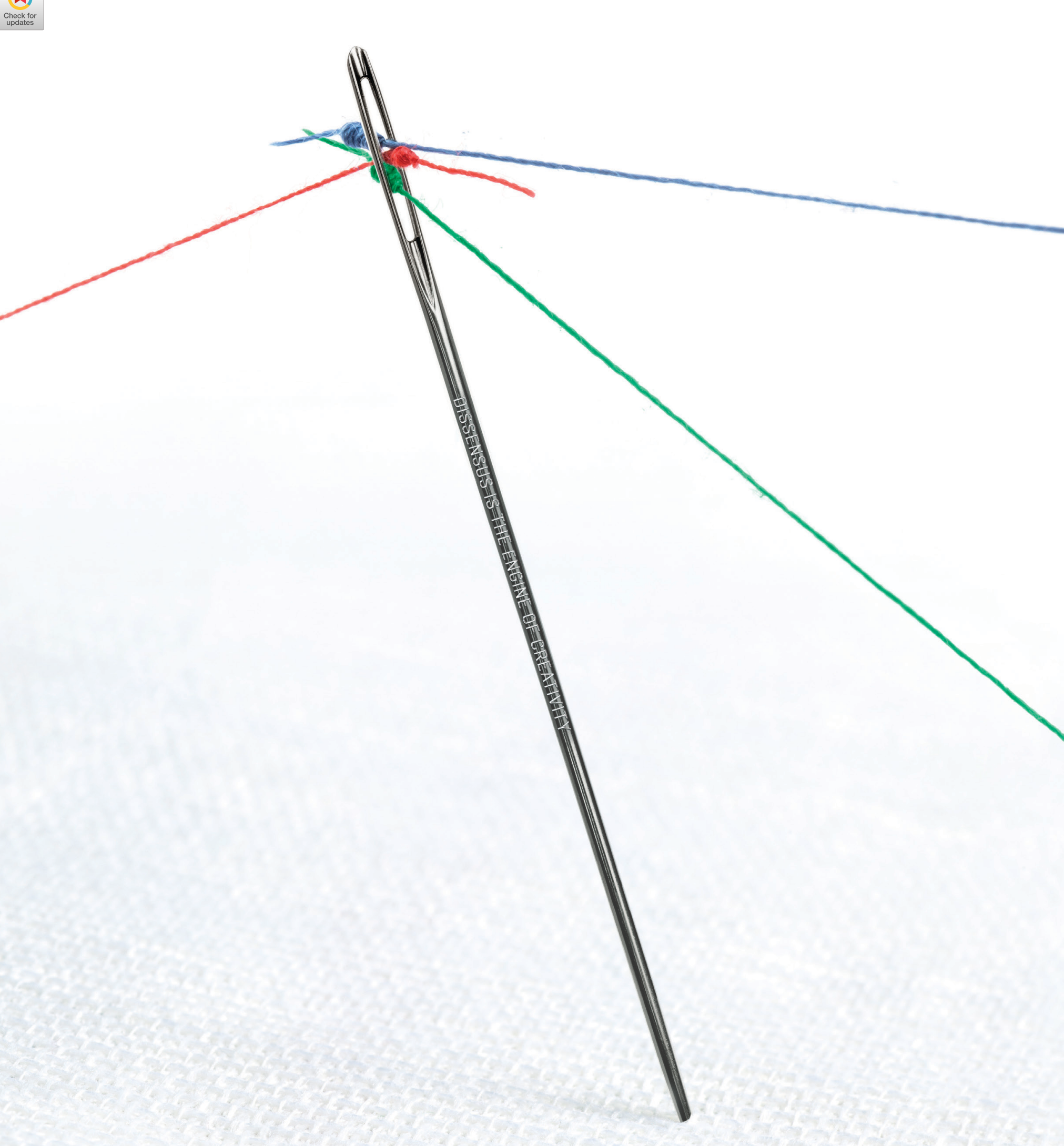




\section{The Politics and}

Aesthetics of

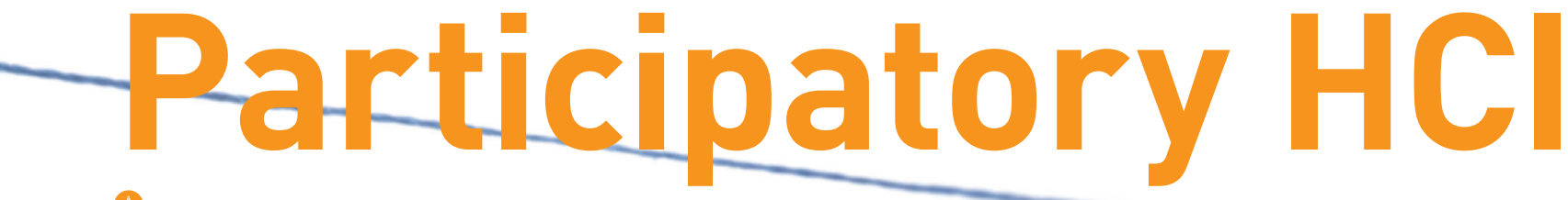

\section{Peter Wright, Newcastle University \\ John McCarthy, University College Cork}

\section{Insights}

$\rightarrow$ Designed properly, participatory projects produce mutual learning and transformative outcomes for all participants.

$\rightarrow$ It is important to consider the logic of participation when designing a project.

$\rightarrow$ The most interesting projects avoid hierarchical positioning and position all participants as skillful, resourceful, situated agents.
Involving users in the design of systems has been a byword in HCI since its inception. The nature and depth of this involvement has varied from identifying needs and requirements to imagining solutions and evaluating outcomes. As different disciplinary perspectives and values have been brought to bear on the design of interactive systems, how user involvement has been understood and configured has also varied. Most recently we are becoming accustomed to working with terms like human-centered design, experience-centered design, participatorydesign, and co-design, which represent the range of different viewpoints and value systems at play in
HCI design research.

This accretion of different perspectives, sensibilities, and ways of thinking about user involvement has enriched HCI discourse and improved HCI research. It has also become an important criterion in assessing research bids for U.K. research funders over the past decade. Despite this success, or perhaps because of it, there is a danger that the ideals of human-centered design and the challenges of delivering real user involvement will be lost in favor of tokenistic enterprises to accommodate funders or journal reviewers.

With this in mind, in our recent book we have attempted to revisit some 


\section{THHEANGEL_OU CEENTREE}

This project is a four-year continuing collaboration between Newcastle University's Open Lab and a community center for black, Asian, minority, ethnic, and refugee women. Rachel Clarke, a community-based artist and digital interaction designer, began working with the Angelou Centre first as a volunteer and then as part of her Ph.D. research. Many of the women who visit the center have experienced arranged marriage, abuse, divorce, and ensuing immigration issues. Clarke worked with a group of women to explore and share their stories through a workshop process of digital portrait making that led to the co-design of a digital photo-sharing system called Photo Parshya. All women and staff were invited to the workshops. Attendance varied but there was a regular core of about six women. The project was very open with no stated commitments to building a digital system before the project began. Building up trust through working as a volunteer, working from the center as a base, and taking time to explore each side's hopes and aspirations for the collaboration were all essential to the success of this project. Clarke helped with a successful follow-on funding award to the center as part of her research. (For further details see [9])

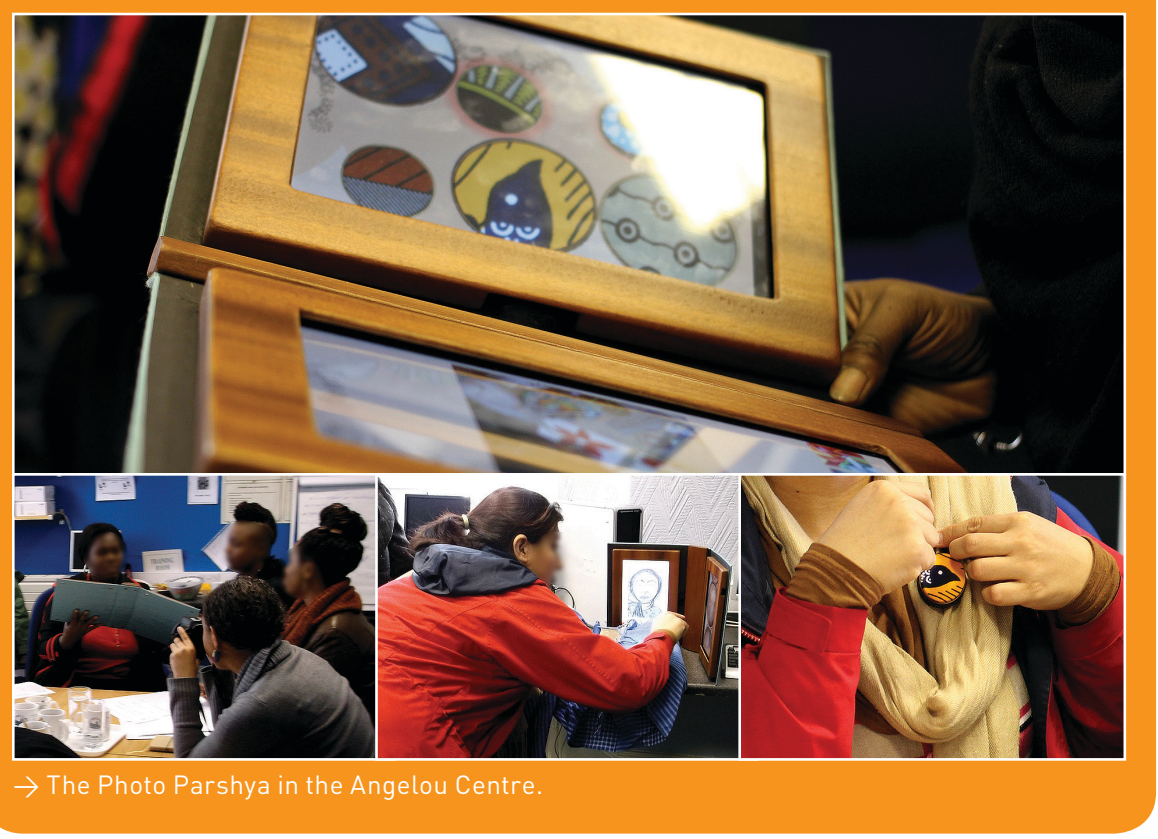

fundamental principles and aspirations around involving users in design [1]. We have done this by exploring participation in HCI projects from the inside, asking how the people who take part in participatory HCI projects make sense of their experiences, how participatory projects are configured and by whom [2], and what the political, ethical, and aesthetic consequences of participation are. Here, we hope to give a sense of what we have learned. To help us explore the whys and wherefores of participation, we will structure this article around a few critical questions and, in attempting to answer them, offer some examples of participatory projects in which we have been involved that illustrate key points.

Is participation an unqualified good? It is easy to assume that participatory HCI is an unqualified good. Supporting the involvement of local people's perspectives and priorities rather than imposing the design from the outside seems inherently right and justified on the grounds of empowerment, democracy, and sustainability. Such values are seen by many as ethical imperatives in any project, especially when power is distributed unevenly. Yet Bill Cooke and Uma Kothari, writing about the gap between rhetoric and practice in participatory development projects, reported that practitioners and participants had become cynical about ritualistic, manipulative practices that although meant to empower, were more likely to harm local communities and participants [3]. Although public discourse on participatory development treated it as an unquestioned good, insider conversations cynically recognized the need to promote participation while doubting its value. Cooke and Kothari wondered whether participatory development had become so irreproachable as to become a tyranny. The tyranny of participation is that in practice it can result in political cooption; it can require contributions from participants in the form of unpaid labor, cash, or time, in effect transferring some of the costs of the project to the participants. Equally, relationships within a project can be managed in ways that mean local practices and knowledge, rather than shaping design decisions, are structured by them. The risk of similar cynicism in HCI indicates the need for a critical inquiry into the values of participation in HCI, informed by careful attention to local practices and relationships. How a participatory project is configured, who gets invited, and how participants are positioned all affect the participatory experience and outcomes.

Managed well, participatory projects can produce mutual learning and transformative outcomes for all participants. Managed poorly, they can serve to exploit labor, invalidate local knowledge, neutralize voices, and silence dissent.

The invitation: Who gets to participate? You can tell a lot about a project from who is invited to take part and how. Who gets to participate is often determined by entirely practical issues, but a range of logics of participation construct what is practical.

In traditional human-centered design projects, there is usually a drive to involve those whose jobs and lives will be affected by the technology being designed and deployed. In most cases, it is not possible to include everyone. Those who do get to participate often do so on the basis of being domain experts, who have extensive knowledge of local practices and thus are able to speak for other workers from that position of expertise. In such cases, the logic of participation is one in which the participants stand as proxy for those whose lives will be affected by the project but who are not included in it.

A contrasting logic of participation is the logic of representative sampling. Although most common in psychological experiments, this can also be used in major public consultations. For example, Listening to the City was a planning consultation project about the future of the Ground Zero site in New York that used representative sampling [4]. The logic of representative sampling is first to identify a target population or market, then identify the different demographics within that population (who may 
respond differently as a consequence of, for example, socioeconomic status), and finally to sample randomly from within those segments. It is argued that through this process, those who take part are truly representative of the range and diversity of views within the target population. Here the participants are no longer speaking on behalf of others (the logic discussed previously). Rather, they are representative in the instrumental or statistical sense, in that they are assumed to think and act in the same way as the larger population from which they are sampled.

Representative sampling requires the involvement of a large number of participants. Within participatory HCI projects, such large-scale participation is often practically impossible. Consequently, these projects often involve only between five and 25 participants. These smaller-scale projects are characterized by a different range of logics. In some cases, the invitation is made to all of those assumed to be interested in or affected by the project, and participants are left to selfselect. Those who opt in are assumed to be the people who are most interested in the process or outcomes, and those who self-select out are assumed to be uninterested. In these projects, what will be designed or whether anything will be designed is often not decided before the invitation to participate has been issued and accepted (see the sidebars on the Personhood and the Angelou Centre projects, for example). In some cases, it is hoped that those who take part will find something meaningful, memorable, or even life-changing in the process or in what is produced. In other cases, participants volunteer their services not just because they themselves will benefit but rather because they want to try to improve quality of life for people like them or even for the general public (see the sidebar on the BOSOP project),

When deciding who will participate, it is important to articulate the logic of participation that is in play.

How are participants positioned by a project invitation? These different logics of participation construct a variety of subject positions in participatory projects. Subject positions are the identities jointly produced through the interactions made possible by the different logics of participation; they influence how participants see themselves and are seen by others. The subject positions created by a given logic are important to consider because a given subject position makes available or visible to participants a certain set of action potentials, while rendering others invisible or unavailable. The configuration of action potentials normalizes what individuals can do, say, and think, and what counts as a valid contribution. The extent to which action potentials are preconfigured or left open to evolve can lead to important differences in the quality of participatory projects. For example, in a standing as proxy logic, someone positioned as a domain expert is expected to help the designers better understand the experiences of their colleagues and the requirements of the domain. In return they expect to influence decisions about what will be designed.

Participants' subject positions are often configured by those who own the idea, finances, or resources. In many projects, this is the design team, who often position themselves at the center of the project. Lucy Suchman reports that in some of these cases, the end user is positioned by the team as the "the unruly other," someone who is likely to disturb their carefully controlled processes, a stranger and an outsider who needs to be tamed and trained [5]. But even when taken seriously by designers as a source of knowledge, end users can still be positioned in many different ways. For example, in a codesign project, they are positioned as agents with a voice and authorship over what is done and co-ownership of what is produced. Whereas in traditional user-centered projects, they are more often positioned as passive sources of information about the domain, or as informants used to determine which of two or more design alternatives are preferred, alternatives that they did not have a say in constructing.

Key considerations when designing an invitation to participate are what subject positions are being configured by the invitation, and to what extent the project is designed to leave subject positioning open to negotiation or self-organization.

The most interesting participatory projects avoid hierarchical positioning and configure all participants as skillful, resourceful, situated agents taking part in creative experiences they would not otherwise have had, while remaining open to issues of ownership, authorship, and voice.

Where does participation take place? Decisions about the site of participation - where meetings will be held — are also significant in positioning participants. Is the user being invited to move from the space of their own experience to that of the designers or

\section{JACOB HOUSSE PROJIECT}

Jacob House was a council-funded residential care home for elderly people. The person running the care home was excited to take part in a project geared toward giving her residents new ways of engaging with the Web. But the project team faced a major challenge: encouraging residents and care staff to participate in the project. Researcher Mark Blythe knew a local artist, Phil Reynolds, who had worked in a care home previously and who was interested in getting involved again. He began by painting residents' portraits. This created a space in which silence, conversation, and observation could all occur fairly easily without straining the residents. This activity grew, with other artists joining in, and an art club from a local school also becoming regular visitors. The art projects created space for residents and team members to develop roles for themselves in which the residents had a say, and through which they could sometimes give voice to their sense of themselves. This arrangement was more clearly negotiated than a series of interviews would have been. (For further details see [10])

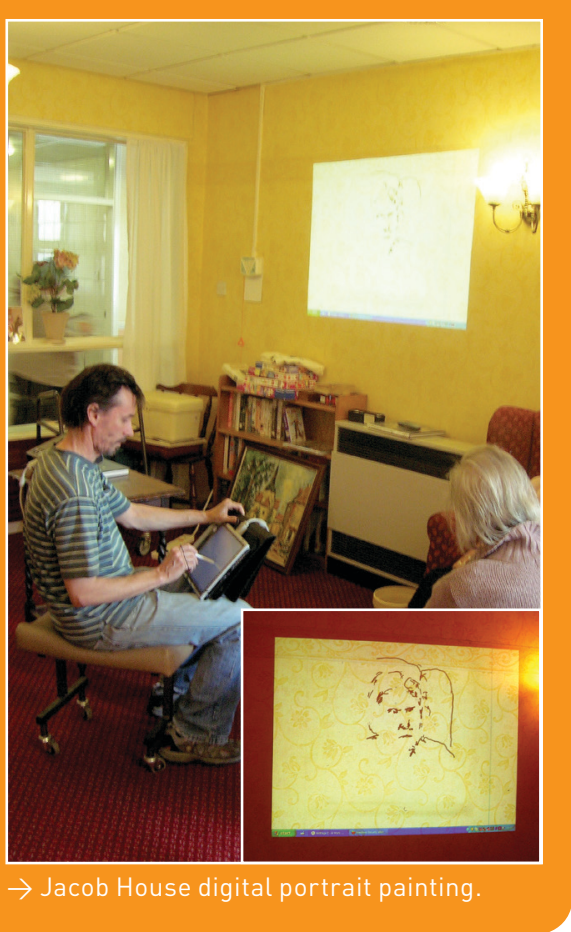


vice versa? This is about the choice to encounter people in places where they already have a voice, an identity, and a reputation. The important thing is that the choice should create a situation where conversation, deliberation, and relationship building can keep the diversity of voices alive.

Many participatory projects in HCI involve a deeply situated engagement with people in their own life worlds. Going into those places where participants live and have control over their own experiences involves encountering people where they already have a voice. These are also places in which recognition of the voices of researchers and designers cannot be assumed. In such settings, researchers and designers have to spend time establishing their identity, explaining what they are about, and making it clear they understand they are operating in the other's place, where they are outsiders and have to find or even create roles for themselves. In these cases, researchers have to learn about the ways in which they may be allowed to participate, not just about how other participants might want to participate. In both the Jacob House and the Angelou Centre projects (see sidebars), the researchers responded to participants' caution, resistance, or antagonism by finding ways to bring the already active voices of the participants to the fore, avoiding the kind of crude or tokenistic participation that draws people into activities of which they feel no ownership. In contrast, in the BOSOP project, participants were invited to meetings held at the university because researchers considered it to be a neutral ground between the hospital and the patients' homes. This choice affected the experience of both staff and patients, most of whom had never been inside a university, with some referring to their visits as "going on a course."

The choice of place for meetings, workshops, and other forms of interaction is an important factor in framing participants' expectations about what the relationship between themselves and other project members will be. This can affect not only motivation and commitment but also what can be said, seen, and discussed.

Be prepared to experience disinterest, distrust, resistance, and even antagonism when trying to configure a participatory project.

\section{What is the value of participatory}

projects? The main reason for configuring a design project as participatory is to use the project to open up spaces and opportunities for people with different experiences and viewpoints - with the goal of creating something together that they could not have created alone. In such projects, the assumption is that designers and participants have something to learn from each other, precisely because they start from different points of view, with different experiences and different subject positions. Difference has to

\section{THHE PEERSONHTOOD PROJJECT}

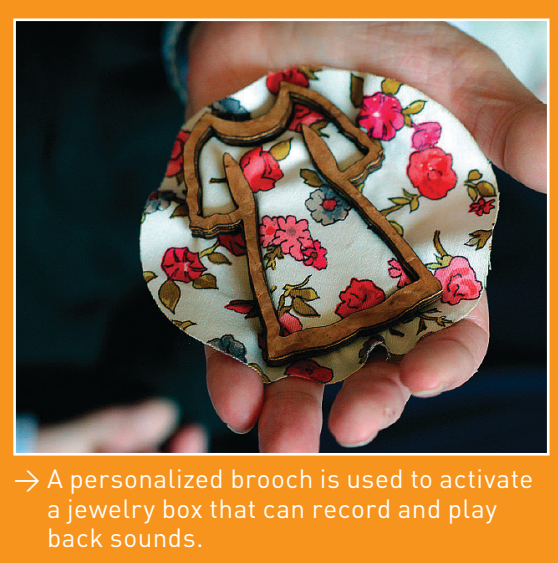

Jayne Wallace worked through the Alzheimer's Society, inviting people with dementia and their caregivers to two introductory meetings, where they expressed interest in taking part in the project. Two couples volunteered from these meetings; one couple later dropped out. Wallace worked with Gillian, who at the time had mild dementia, and her husband and caregiver John. She visited their home over a long period of time. Her approach invited Gillian and John to participate in a gentle, reciprocal inquiry through a series of conversations that recognized the distinctive roles of each of the three participants. She designed a series of personally crafted probes

to help them share their stories and values with her, creating space for all of them to exercise their creativity, individually and collectively. The process culminated in Wallace making digital jewelry pieces for them. Because the experience of living with dementia is an encounter with the borders of personhood-a particular loved one's personhood-in this project, participants' sense of themselves and each other as living, feeling, thinking people is the point. (For further details see [11]) exist for something new to be created, for people to learn, and for people to be surprised. It is difference, not consensus, that is the engine of creativity. But for difference to be used creatively, it has to be visible.

The philosopher Jacques Rancière referred to what can be said, seen, heard, thought, and talked about within a particular group, community, or society as the sensible [6]. What is sensible and what is not sensible is controlled or, to use Rancière's term, policed, within a group by making certain things commonsense, and thus not open to question. People rely on commonsense, including common ground, shared viewpoints, and agreement around issues to build consensual interactions because they reinforce solidarity, common purpose, and agreed-upon action plans. But consensus built on commonsense by definition stifles different viewpoints, different ways of seeing, hearing, thinking, and talking. The value of well-designed participatory projects is not only that they bring together diverse participants with different perspectives and different experiences, but also that they configure spaces for imagination and dialogue that make those differences sensible as well as acceptable and valuable. Such projects reconfigure the sensible to create situations and encounters between differently placed participants that allow them to see and acknowledge the difference between each party's way of seeing, talking, and thinking, and use this difference to create new imaginaries. Rancière refers to this process of innovation as dissensus.

Dissensus challenges the current hierarchy and the consensual policing of the sensible. It is a creative act of questioning that which is commonly accepted without thought or question. Although consensus is defined by a distribution of the sensible that makes its rules commonsense and thus unquestionable, dissensus is characterized by an "innovative leap from the logic that ordinarily governs human situations" [7]. This innovative leap requires an ability first to imagine and then to articulate an alternative logic or a different way of seeing that offers a meaningful way of going on. The value of participatory projects is their ability to configure spaces in which dissensus is made sensible, acknowledged, and used constructively. 


\section{BOSOP}

Better Outpatient Services for Older People (BOSOP) was a oneyear project with a local hospital to bring together 12 older patients and caregivers, some patient advocates from a voluntary organization, nine hospital staff, and designers. The process involved a gradual buildup of the team through small incremental events to build mutual trust and understanding. The aim of the project was to share experiences and codesign service improvements. The research team was keen to emphasize participants shared ownership of the project.

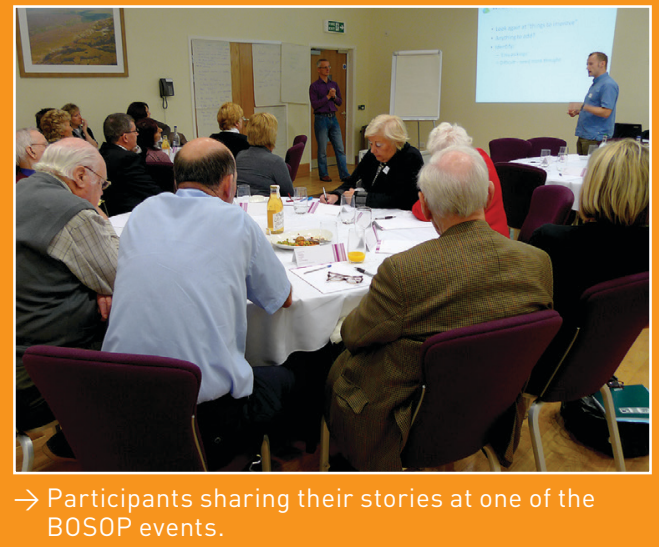

Initially members of the research team met patients and advocates to talk to them, reassure them, and gather stories of their experience. Then two half-day events were held, one for patients and caregivers and one for staff, to share their experiences and stories among themselves. The staff and outpatients then came together to exchange stories. In a final phase, participants then formed two co-design teams to discuss those areas and to propose improvements. Participants' understanding of the project and their roles in it as agents of change evolved only gradually throughout the project, and the process was marked by dissensus and consensus. For example, initially when patients shared their experiences, staff became defensive, identifying resource limitations and logistical demands rather than listening to how patients felt. The design team regularly restated the aim of understanding what it feels like from the other person's perspective. Time working on the project and small victories along the way helped build up a level of trust and common ground between staff and patients, including moments of sharing frustrations. (For more detail see [12])

Dissensus is the engine of creativity. Participatory projects reconfigure what is sensible to create space for dissensus, making previously unimaginable possibilities for action thinkable.

Why is HCI interested in participatory projects? HCI as a discipline has always thrived on dissensus. Initially, psychologists and computer scientists challenged unquestioned assumptions about how to design and develop technology and how to make sensible constructs like the user and usability "new subjects and new heterogeneous objects" [7]. Later work challenged unquestioned assumptions about distinctions among designers, users, and technology. There has also been an impetus to explore new ways of doing research and constituting the interdisciplinary field, and to bring new disciplines into dialogue. Learning with and from participants and from a variety of disciplines has been an engine of change within $\mathrm{HCI}$ as its digital imaginary has evolved. The idea of HCI as an interdiscipline captures something of the way in which it dwells in between other disciplines to form a fluid and responsive practice [8]. Its community exists in a kind of outside belonging [1] neither computer science, psychology, engineering, design, art, nor science. Outside belonging is a dissensual existence, and it is one of HCI's major strengths when dealing with the social contexts out of which thinking and feeling emerge, and when designing on the threshold between the individual and the collective.

\section{ACKNOWLEDGMENTS}

The research presented here was supported by the RCUK SIDE Digital Economy Research Hub (EP/G066019/1), the RCUK New Dynamics of Ageing Programme (ES/F015925/1), The UK NIHR CLAHRC-South Yorkshire UCHD project, and the AHRC Creative Exchange Research Hub (AH/J005150/1).

\section{ENDNOTES}

1. McCarthy, J. and Wright, P. Taking [A]Part: The Politics and Aesthetics of Participation in Experience-Centered Design. MIT Press, 2015.

2. Vines, J., Clarke, R., Wright, P., McCarthy, J., and Olivier, P. Configuring participation: On how we involve people in design. Proc. of CHI 2013. ACM, New
York, 2013, 429-438.

3. Cooke, B. and Kothari, U. Participation: The New Tyranny? Zed Books, 2001.

4. Civic Alliance to Rebuild Downtown New York. Listening to the City: Report of Proceedings. 2002; http://americaspeaks. org/wp-content/_data/n_0001/resources/ live/final_report_ltc3.pdf

5. Suchman, L. Human-Machine Reconfigurations: Plans and Situated Actions (2nd edition). Cambridge Univ. Press, 2007.

6. Rancière, J. Dissensus: On Politics and Aesthetics. Bloomsbury, 2010.

7. Corcoran, S. Editor's introduction. In Rancière, J. Dissensus: On Politics and Aesthetics. Bloomsbury, 2010.

8. Blackwell, A.F. HCI as an interdiscipline. Proc. of the 33rd Annual ACM Conference Extended Abstracts on Human Factors in Computing Systems. ACM, New York, 2014, 503-516.

9. Clarke, R., Wright, P., and McCarthy, J. Sharing narrative experience: Digital stories and portraits at a women's centre. CHI 2012 Extended Abstracts of ACM Human Factors in Computing Systems Conference. ACM, New York, 2012, 1505-1510.

10. Blythe, M., Wright, P., Bowers, J, Boucher, A., Jarvis, N., Reynolds, P., Gaver, B. Age and experience: Ludic engagement in a residential care setting. Proc. of DIS 2010. ACM, New York, 2010, 161-170.

11. Wallace, J., Wright, P., McCarthy, J., Green, D., Thomas, J., and Olivier, P. A design-led inquiry into personhood in dementia. Proc. of CHI 2013. ACM, New York, 2013, 2617-2626.

12. Wolstenholme, D., Cobb, M., Bowen, S., Wright, P., and Dearden, A. Design-led service improvement for older people. Australasian Medical Fournal 3, 8 (2010), $465-470$.

(4) Pete Wright is professor of social computing at Open Lab (www.openlab.ncl. ac.uk), Newcastle University, U.K., and codirector of the EPSRC Centre for Digital Civics (http://digitalcivics.org.uk). His research area is the human-centered and participatory design of digital systems. With John McCarthy, he is best known for Technology as Experience (MIT Press, 2004), Experience-Centred Design (Morgan Claypool, 2010), and Taking [A]Part (MIT Press, 2015).

$\rightarrow$ p.c.wrightancl.ac.uk.

(1) John McCarthy (http://patlab.ucc.ie/ people/professor-john-mccarthy/) is professor of applied psychology at University College Cork, Ireland, where he leads the People and Technology Group. His current research includes (i) developing dementia-friendly research communities that do experiencecentered design with people with dementia and their carers and (ii) exploring digital publics as expression of civic engagement.

$\rightarrow$ john.mccarthy@ucc.ie 